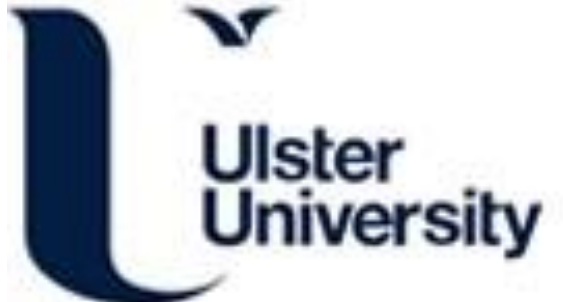

\section{Theoretical modeling and finite element simulation of dilution in micro-plasma transferred arc additive manufacturing of metallic materials}

Sawant, M. S., Jain, N. K., \& Nikam, S. H. (2019). Theoretical modeling and finite element simulation of dilution in micro-plasma transferred arc additive manufacturing of metallic materials. International Journal of Mechanical Sciences, 164, 1-12. [105166]. https://doi.org/10.1016/j.ijmecsci.2019.105166

Link to publication record in Ulster University Research Portal

\section{Published in:}

International Journal of Mechanical Sciences

Publication Status:

Published (in print/issue): 01/12/2019

DOI:

10.1016/j.jjmecsci.2019.105166

\section{Document Version}

Author Accepted version

\section{General rights}

Copyright for the publications made accessible via Ulster University's Research Portal is retained by the author(s) and / or other copyright owners and it is a condition of accessing these publications that users recognise and abide by the legal requirements associated with these rights.

\section{Take down policy}

The Research Portal is Ulster University's institutional repository that provides access to Ulster's research outputs. Every effort has been made to ensure that content in the Research Portal does not infringe any person's rights, or applicable UK laws. If you discover content in the Research Portal that you believe breaches copyright or violates any law, please contact pure-support@ulster.ac.uk. 


\title{
Theoretical modelling and finite element simulation of dilution in micro-plasma transferred arc additive manufacturing of metallic materials
}

\author{
Mayur S. Sawant ${ }^{1}$, N. K. Jain ${ }^{2 *}$, Sagar H. Nikam ${ }^{3}$ \\ ${ }^{1}$ Postdoctoral Fellow, ${ }^{2}$ Professor, Discipline of Mechanical Engineering, \\ Indian Institute of Technology Indore, Simrol, 453552 (MP) India \\ ${ }^{3}$ Research Associate, School of Computing, Engineering and Intelligent Systems, \\ Ulster University, Derry/Londonderry BT48 7JL, Northern Ireland, UK \\ * Corresponding author: nkjain@ iiti.ac.in; phone +91 7324306 989; Fax: +91 7312438721
}

\begin{abstract}
Dilution in any additive layer manufacturing signifies fusion of a deposition layer with the substrate as well as between the successive deposited layers. It assumes importance because it affects metallurgical bonding and properties of the deposited layers. Evaluation of dilution of a deposition by optical microscopy is more accurate but it is destructive due to requirement of the sample preparation. Monitoring and control of the dilution is also very difficult. Dilution can be predicted either by a theoretical model or finite element simulation (FES). This paper presents development of a generic theoretical model and FES to predict dilution of depositions by micro-plasma transferred arc additive manufacturing (MPTAAM) process. The model and FES predicted values were validated by comparing them with the experimental results of single-layer single-track deposition of Ti-6Al-4V powder on the substrate of the same material for the various parametric combinations of MPTAAM process. Results have shown very good agreement between model and FES predicted values of dilution with the corresponding experimental values. The developed theoretical model is also generic because it depends only on the MPTAAM process parameters and thermal properties of the deposition and substrate materials thus making it applicable for any combination of deposition and substrate materials and for any form of the deposition material. The results showed that dilution increases with increase in microplasma power and relative speed between the worktable and deposition head whereas decreases with increase in volumetric feed rate of the deposition material.
\end{abstract}

Keywords: Additive manufacturing; Dilution; Micro-plasma; Theoretical model; Finite element simulation

\section{Nomenclature}

$A_{d}$

$A_{s}$

$C$

$C_{p d}$

$C_{p s}$

$C_{p s}^{*}$
Area of the deposited material $\left(\mathrm{m}^{2}\right)$

Area of the diluted substrate material $\left(\mathrm{m}^{2}\right)$

Correction factor to modify thermal conductivity of the substrate material

Specific heat of the deposition material (J/Kg K)

Specific heat of the substrate material (J/Kg K)

Modified value of specific heat of the substrate material (J/kg K) 


\begin{tabular}{|c|c|}
\hline$C_{p s}$ & Specific heat of the substrate material $(\mathrm{J} / \mathrm{Kg} \mathrm{K})$ \\
\hline$E_{\text {melt }}$ & Energy used for melting the deposition and substrate materials (J) \\
\hline$E_{S}$ & Total energy supplied to the heat source (J) \\
\hline$E_{\text {sub }}$ & Energy transferred to the substrate $(\mathrm{J})$ \\
\hline$f_{V}$ & Volumetric feed rate of the deposition material $\left(\mathrm{m}^{3} / \mathrm{s}\right)$ \\
\hline$h_{\text {conv }}$ & Convective heat transfer coefficient for substrate material $\left(\mathrm{W} / \mathrm{m}^{2} \mathrm{~K}\right)$ \\
\hline$h_{d}$ & Height of deposition (m) \\
\hline$h_{m}$ & Height of the melt pool (m) \\
\hline$\Delta H_{d}$ & Change in enthalpy of the deposition material $(\mathrm{J} / \mathrm{kg})$ \\
\hline$\Delta H_{s}$ & Change in enthalpy of the substrate material $(\mathrm{J} / \mathrm{kg})$ \\
\hline$K_{S}$ & Thermal conductivity of the substrate material $(\mathrm{W} / \mathrm{m} \mathrm{K})$ \\
\hline$K_{S}^{*}$ & Modified value of thermal conductivity of the substrate material $(\mathrm{W} / \mathrm{m} \mathrm{K})$ \\
\hline 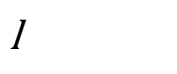 & Length of the deposition (m) \\
\hline$L$ & Stand-off distance between the substrate and micro-plasma torch (m) \\
\hline Lfs & Standard latent heat of fusion of the substrate material $(\mathrm{J} / \mathrm{kg})$ \\
\hline \multirow[t]{2}{*}{$n$} & Unit vector normal to the surface of the molten pool in terms of unit vectors \\
\hline & $i, j, k$ along $X, Y$ and $Z$ axes respectively. \\
\hline$P$ & Micro-plasma power (W) \\
\hline$q(X, Y, Z)$ & $\begin{array}{l}\text { Theoretical heat flow rate at a point having coordinates } \mathrm{X} \text { and } \mathrm{Y} \text { with } \\
\text { respect to the center of a heat source and } \mathrm{Z} \text { with respect to stand-off } \\
\text { distance }\left(\mathrm{W} / \mathrm{m}^{3}\right)\end{array}$ \\
\hline$q$ & Actual heat flow rate $\left(\mathrm{W} / \mathrm{m}^{3}\right)$ \\
\hline$r_{m}$ & Radius of micro-plasma arc (mm) \\
\hline$t$ & Instant of time at which micro-plasma arc strikes the substrate material (s) \\
\hline$t_{d}$ & Deposition time (s) \\
\hline$T$ & Instantaneous temperature of melt pool at time $t(\mathrm{~K})$ \\
\hline$T_{i}$ & Ambient temperature (298 K) \\
\hline$T_{m d}$ & Melting temperature of the deposition material (K) \\
\hline$T_{m s}$ & Melting temperature of the substrate material (K) \\
\hline$V_{d}$ & Volume of the deposited material $\left(\mathrm{m}^{3}\right)$ \\
\hline$V_{s}$ & Volume of the diluted substrate material $\left(\mathrm{m}^{3}\right)$ \\
\hline $\mathrm{V}$ & Voltage applied to micro-plasma arc (Volts) \\
\hline$V$ & Relative speed between the worktable and deposition head (m/s) \\
\hline
\end{tabular}




$\begin{array}{ll}W_{p} & \text { Weight of deposition material delivered to the melt pool }(\mathrm{g}) \\ W_{s} & \text { Weight of the substrate material }(\mathrm{g}) \\ W_{t} & \text { Combined weight of the deposition and substrate materials }(\mathrm{g}) \\ W_{m} & \text { Width of melt pool }(\mathrm{m}) \\ \alpha_{s} & \text { Thermal diffusivity of the substrate material }\left(\mathrm{m}^{2} / \mathrm{s}\right) \\ \varepsilon_{s} & \text { Emissivity of the substrate material } \\ \eta_{a} & \text { Micro-plasma energy transfer efficiency }(\%) \\ \eta_{d} & \text { Deposition efficiency (\%) } \\ \eta_{m} & \text { Melting efficiency (\%) } \\ \rho_{d} & \text { Density of the deposition material }\left(\mathrm{kg} / \mathrm{m}^{3}\right) \\ \rho_{s} & \text { Density of the substrate material }\left(\mathrm{kg} / \mathrm{m}^{3}\right) \\ \sigma_{e s} & \text { Electrical conductivity of the substrate material }\left(\mathrm{ohm}^{-1} \mathrm{~m}^{-1}\right) \\ \sigma_{s b c} & \text { Stefan-Boltzmann constant }\left(5.67 \mathrm{x} 10^{-8} \mathrm{~W} / \mathrm{m}^{2} \mathrm{~K}^{4}\right)\end{array}$

\section{Introduction}

Additive manufacturing (AM) is a bottom-up manufacturing approach in which a product is manufactured directly from its computerized model by depositing the material in thin successive layers in such a way that good mechanical properties and dimensional and geometrical accuracy are achieved along with sound metallurgical bonding between the deposited layers [1]. AM processes have ability to manufacture complex parts of diverse materials [2], repair and/or remanufacture the damaged components [3], modify surfaces of a product by coating, computer aided manufacturing (CAM) [4], on-line inspection, monitoring, control [5] and material-efficient than conventional processes due to very small loss of the product material [6]. Therefore, AM has generated a lot of research interests and industry expectations in the recent times. Various AM processes can be primarily categorized according to type of the energy source and form (i.e. wire, powder, particulate, flakes, sheet) of the deposition material used by them. Arc [such as plasma transferred arc (PTA), gas tungsten arc (GTA), gas metal arc (GMA), etc.] and energy beam (i.e. laser or electron beam) are the most commonly used heat sources. Sawant and Jain [7] developed a novel AM process for the metallic materials and referred it as micro-plasma transferred arc additive manufacturing (MPTAAM) process as an alternative to the existing AM processes. Same authors [8] proved this process to be cost-effective, material-efficient, energy-efficient, and consequently environment-friendly than laser-based and PTA based depositions processes. Sawant and Jain [9] compared Stellite coatings manufactured through powder deposition by MPTAAM process, 
PTA deposition and laser deposition processes to prove superiority of quality of deposition by MPTAAM process. They observed that Stellite coatings by laser deposition and MPTAAM had stronger metallurgical bond, lesser distortion of the substrate, lower dilution, smaller HAZ, and absence of defects than those by PTA deposition. Despite several advantages of MPTAAM process, its control over geometry of the deposition is still difficult. This is mainly due to complex relationship among thermo-physical properties of the deposition and substrate materials, process parameters (i.e. relative speed between the worktable and deposition head, volumetric feed rate of the deposition material and micro-plasma power) and the deposition characteristics (i.e. deposition height and width, dilution, cooling rate, metallurgical characteristics) [2]. Various process parameters are required to be controlled continuously and simultaneously to ensure good quality of deposition. Deposition height and width can be easily monitored and measured by a vision apparatus however, dilution and metallurgical characteristics cannot be measured directly. Dilution is ratio of volume of the diluted substrate material ' $V_{s}$ ' to sum of volume of the deposited material ' $V_{d}$ ' and volume of the diluted substrate material ' $V_{s}$ ' with both being separated by the fusion line as depicted in Fig. 1 and as represented by Eq. 1 .

$$
\text { Dilution }=\frac{V_{s}}{\left(V_{s}+V_{d}\right)} \times 100
$$

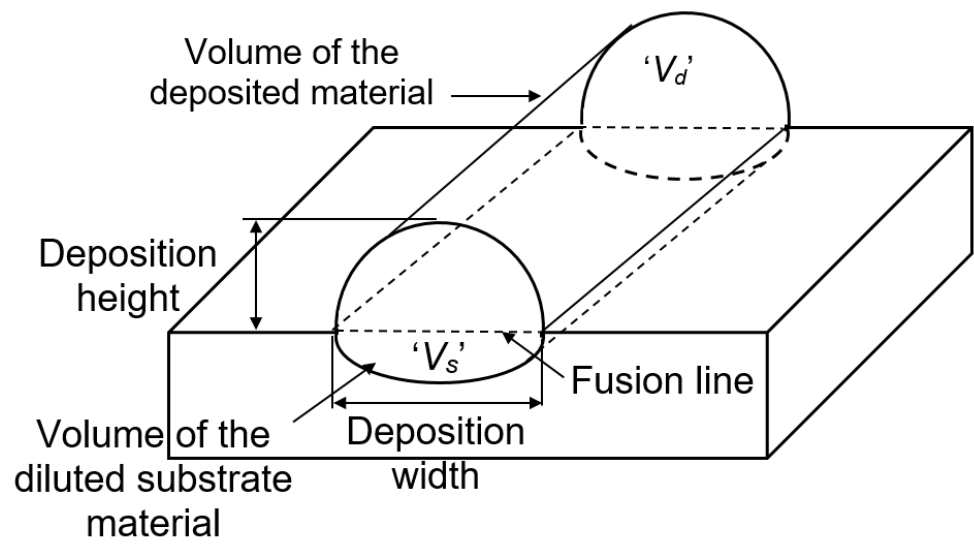

Fig. 1: Concept of deposited and diluted volumes used in computation of dilution.

If the profile of the deposition geometry is assumed to remain constant along length of the deposition, then dilution can be computed replacing $V_{s}$ by dilution area and $V_{d}$ by deposition area. Dilution is an important parameter for any AM process because it quantifies the relative amount of fusion of the deposited layer with the substrate as well as bonding between the different deposited layers. Higher value of dilution of deposition lowers corrosion resistance and mechanical properties of the coatings and increases the distortion whereas, very less value 
of dilution leads to poor bonding between two successive layers as well as the substrate [8]. Dilution can be measured by analysing optical images of the deposited layers but, it is destructive due to requirement of sample preparation. It can be predicted by two possible methods i.e. theoretical model or finite element simulation (FES).

Analytical and numerical models for different deposition characteristics have been proposed in the literature. Liu and $\mathrm{Li}$ [10] proposed a model for laser cladding process to predict deposition width in terms of laser scanning velocity, flow rate of deposition material and laser power. The model predicated results were validated experimentally and found to be in good agreement with experimental values. Hua et al. [11] analyzed effects of laser scan speed, laser spot diameter, laser power, powder feed rate, angular position of powder feeding nozzle and flow rate of shielding gas on distribution of temperature within the melt pool formed during laser rapid deposition process. Tan et al. [12] developed 2D-transient model using moving square heat source for laser additive manufacturing by considering uniform heat distribution and used it to estimate thickness of the deposited wall and temperature distribution in thin-wall structures. Cheikh et al. [13] predicted dimensions of cross-section of the deposition geometry obtained by direct laser deposition process using a numerical and a regression model. Both the models were validated using the experimental results and found to be good agreement. Jhavar et al. [14] developed model to predict cross-section area of deposition geometry obtained by micro-plasma transferred arc wire additive manufacturing (MPTAWAM) process considering profile of deposition geometry as an arc of ellipse. They mentioned that the developed model can be used to optimize the overlap distance between the multi-track deposition. Ya et al. [15] developed 2D-thermal model for laser cladding process in terms of process parameters and powder efficiency using mass and energy balance equation. The model predicted results were found to be in good agreement with the experimental values. Nikam et al. [5] used fundamental principles of energy balance and heat transfer to develop a thermal model to predict width and height of single-track deposition by MPTAWAM process in terms of micro-plasma power, relative speed between the worktable and deposition head and volumetric feed rate of the deposition material. The developed model is dependent on thermal properties of the substrate and deposition materials only and is does not depend on form of the deposition material therefore it can used for any combination of substrate and deposition materials and for any form of the deposition material. Nikam and Jain [16] used 3D-FES to analyze temperature distribution and thermal cycles in multi-layer metallic deposition by MPTAAM process using temperature dependent properties of the deposition material. They found that increase in deposition height increases maximum temperature of thermal cycles due to effect of heat 
transfer on the deposited layer before and after deposition leading to thermal distortion and thermal stresses in the substrate material. They also studied effect of deposition direction on temperature distribution and temperature gradient in multi-layer metallic deposition and found that parallel deposition has higher thermal gradient thus better heat diffusion than the back and forth deposition. They verified the simulated results with experimental results obtained by deposition of Ti-6Al-4V powder on same material substrate. Shreshta et al. [17] developed thermo-fluid 3D model for electron beam melting process. They investigated effects of scanning speed on the surface roughness and observed increase in surface roughness increases with scanning speed. Lee et al. [18] used response surface method (RSM) to formulate regression equations to predict deposition geometry and dilution depth as function of parameters of laser direct energy-based deposition process. They studied effects of process parameters on cross-sectional profile of single-layer single-track deposition geometry. The model predicted results were found to be in good agreement with experimental results. Nabhani et al. [19] used linear regression analysis to develop empirical-statistical relations between characteristics of single-layer single-track (i.e. track height, track width, penetration depth, wetting angle, and dilution) and power, travel speed and deposition material feed rate for laser cladding process. Experimental validation confirmed that the developed relations predicted the characteristics of single-layer single-track depositions with good accuracy. Reddy et al. [20] proposed models for the laser deposition process to predict the porosity, deposition efficiency and dilution. They found that deposition efficiency and dilution is dependent on the process parameters whereas porosity is not.

Following conclusions can be made from review of the relevant past work: (i) deposition characteristics in an AM process are significantly affected by its parameters and thermophysical properties of the deposition and substrate materials, and (ii) models have been developed to predict deposition geometry such as height and width only, (iii) generic theoretical model has not been developed to predict dilution for real-time control applications. Therefore, objective of this paper is to develop a generic theoretical model for single-layer single-track deposition by MPTAAM process, predict it using FES and validate both the models experimentally.

\section{Development of Theoretical Model for Dilution}

Theoretical model for dilution of deposition by an AM process can be developed in terms of process efficiencies (i.e. energy transfer efficiency, melting efficiency and deposition efficiency), process parameters and material properties of the deposition and substrate materials using fundamental principles of energy balance equation. Such model should be 
generic in the sense that its applicability should be independent of form the deposition material and combination of the deposition and substrate materials. Following paragraphs describe assumptions made to develop generic theoretical model, concepts of different efficiencies relevant to MPTAAM process, development of theoretical model and finite element simulation of dilution of single-layer single-track deposition by MPTAAM process.

\subsection{Assumptions}

Following assumptions were made to simplify task of development of generic theoretical model for dilution by of single-layer single-track deposition by MPTAAM process:

- Substrate is a semi-infinite block at the ambient temperature.

- Micro-plasma arc is perpendicular to the substrate material and stand-off-distance between deposition head and substrate is constant.

- Shape of melt pool is constant throughout the deposition process.

- Area of melt pool is approximately equal to diluted area.

- Profile of the deposition geometry remains constant along the length of the deposition i.e. dilution can be computed using areas of diluted and deposited materials instead of their respective volumes.

- Thermal properties of the deposition and substrate materials are temperature independent.

\subsection{Different Efficiencies Relevant to MPTAAM Process}

\subsubsection{Micro-plasma energy transfer efficiency}

Micro-plasma energy transfer efficiency ' $\eta_{a}$ ' is the ratio between energy transferred to the substrate ' $E_{s u b}$ ' and the total energy supplied to the heat source ' $E_{s}$ ' i.e. it represents fraction of the total input energy transferred to the substrate material and is expressed as

$$
\eta_{a}=\frac{E_{\text {sub }}}{E_{S}}
$$

Since, mechanism of transferring the micro-plasma energy to substrate is very complex therefore there are many factors that influence $\eta_{a}$. It primarily depends on ionisation of plasma gas, type of plasma gas, flow rate of plasma gas, and various parts of the micro-plasma torch (i.e. electrode, type of nozzle, diameter of nozzle). It significantly affects amount of the heat absorbed by the substrate material, temperature gradient and solidification rate which will in turn affect the resultant microstructure of the deposition.

\subsubsection{Melting efficiency}

Melting efficiency ' $\eta_{m}$ ' is defined as the ratio between the energy used for melting the deposition and substrate materials ' $E_{\text {melt }}$ ' and amount of the energy transferred to the substrate 
' $E_{\text {sub }}$ ' i.e. it represents fraction of the energy transferred to the substrate which is used for the melting it and the rest is lost to the surrounding by thermal conduction. It is expressed as

$$
\eta_{m}=\frac{E_{\text {melt }}}{E_{\text {sub }}}
$$

Few researchers have suggested theoretical relations that can be used to predict the melting efficiency incorporating process parameters, thermo-physical properties of the materials and heat flow conditions. Following modified equation given by Okada [21] has been used in the present work to compute melting efficiency

$$
\eta_{m}=0.4 \exp ^{-\left(1+\frac{\alpha_{s}^{2} \Delta H_{s} \rho_{s}}{1.14 \eta_{a} P v}\right)}
$$

Where, $\alpha_{s}$ is thermal diffusivity of the substrate material $\left(\mathrm{m}^{2} / \mathrm{s}\right) ; \Delta H_{s}$ is change in enthalpy of the substrate material $(\mathrm{J} / \mathrm{kg}) ; \rho_{s}$ is density of the substrate material $\left(\mathrm{kg} / \mathrm{m}^{3}\right) ; \eta_{a}$ is the energy transfer efficiency (\%); $P$ is micro-plasma power $(\mathrm{W})$; and $v$ is the relative speed between the worktable and the deposition head $(\mathrm{m} / \mathrm{s})$.

\subsubsection{Deposition efficiency}

Deposition efficiency ' $\eta_{d}$ ' is measure of deposition material utilization and defined as ratio between amount of the material deposited on the substrate and the amount of deposition material delivered to the melt pool. It can be computed using the following equation:

$$
\eta_{d}=\frac{\left(W_{t}-W_{s}\right)}{W_{p}} \times 100
$$

Where, $W_{t}$ is combined weight of the deposition and the substrate material $(\mathrm{g}) ; W_{s}$ is weight of the substrate material $(\mathrm{g}), W_{p}$ is weight of deposition material delivered to the melt pool $(\mathrm{g})$ which is given by following equation:

$$
W_{p}=\frac{f_{v} t_{d} \rho_{d}}{1000}
$$

Where, $f_{v}$ is volumetric feed rate of the deposition material $\left(\mathrm{m}^{3} / \mathrm{s}\right) ; t_{d}$ is deposition time $(\mathrm{s})$; and $\rho_{d}$ is density of deposition material $\left(\mathrm{kg} / \mathrm{m}^{3}\right)$. Deposition efficiency is significantly affected by design of the deposition material delivery system and AM process parameters.

\subsection{Theoretical Modelling for the Dilution}

Using the fundamental principle of energy balance to equate the total energy available for melting with the energy required to melt the deposition and substrate materials. The energy balance equation is given by

$$
\eta_{a} \eta_{m} P t_{d}=V_{d} \rho_{d} \Delta H_{d}+V_{s} \rho_{s} \Delta H_{s}
$$


Where, $\Delta H_{d}$ is change in enthalpy of the deposition material $(\mathrm{J} / \mathrm{kg})=C_{p d}\left(T_{m d}-T_{i}\right) ; \rho_{d}$ is density of the deposition material $\left(\mathrm{kg} / \mathrm{m}^{3}\right) ; V_{d}$ is volume of the deposited material $\left(\mathrm{m}^{3}\right) ; \Delta H_{s}$ is change in enthalpy of the substrate material $(\mathrm{J} / \mathrm{kg})=C_{p s}\left(T_{m s}-T_{i}\right) ; \rho_{s}$ is density of the substrate material $\left(\mathrm{kg} / \mathrm{m}^{3}\right) ; V_{s}$ volume of the diluted substrate material $\left(\mathrm{m}^{3}\right) ; P$ is micro-plasma power $(\mathrm{W}) ; t_{d}$ is the deposition time (s); $\eta_{a}$ is micro-plasma energy transfer efficiency (\%); and $\eta_{m}$ is the melting efficiency (\%). Rearranging the Eq. 6 to get relationship for volume of the diluted substrate ' $V_{s}$ ' $\left(\mathrm{m}^{3}\right)$ yields the following equation

$$
V_{s}=\frac{\eta_{a} \eta_{m} P t_{d}-V_{d} \rho_{d} \Delta H_{d}}{\rho_{s} \Delta H_{s}}
$$

Volume of deposited material ' $V_{d}$ ' for the powdered form can be calculated using the following relation

$$
V_{d}=\eta_{d} f_{v} t_{d} \Rightarrow \frac{\eta_{d} f_{v} l}{v}
$$

Where, $f_{v}$ is volumetric feed rate of the deposition material $\left(\mathrm{m}^{3} / \mathrm{s}\right) ; \eta_{d}$ is the deposition efficiency $(\%) ; t_{d}$ is deposition time which can be expressed as ratio of length of the deposition ' $l$ ' $(\mathrm{m})$ to relative speed between the worktable and the deposition head ' $v$ ' (m/s). Rearranging Eq. 1 for dilution

$$
D=\left(1+\frac{V_{d}}{V_{s}}\right)^{-1} \times 100
$$

Substituting $V_{s}$ from Eq. 7 and $V_{d}$ from Eq. 8 in Eq. 9 and simplifying gives following expression for computing dilution of single-layer single-track deposition by MPTAAM process in terms of processes parameters and deposition and substrate material properties

$$
D=\left(1+\frac{\eta_{d} \rho_{s} \Delta H_{s} f_{v} l}{\left(\eta_{a} \eta_{m} P t_{d} v\right)-\left(\eta_{d} \rho_{d} \Delta H_{d} f_{v} l\right)}\right)^{-1} \times 100
$$

Following values were used to compute melting efficiency (Eq. 4) and theoretical values of dilution (Eq. 10) for single-layer single-track of Ti-6Al-4V powder on the substrate of same material and assuming that deposition profile remains uniform along the length of deposition:

Micro-plasma energy transfer efficiency ' $\eta_{a}{ }^{\prime}=0.6$ [17]; and deposition efficiency ' $\eta_{d}$ ' $=$ 0.83 as per discussion in section 4 ; Length of deposition ' $l$ ' $=0.045 \mathrm{~m}$; Time of deposition time ' $t_{d}$ ' $=51.9$ (which is calculated as ratio of length of deposition to relative speed between the worktable and deposition head); Melting temperature of substrate material ' $T_{m s}$ ' and deposition material ' $T_{m d}$ ' $=1885 \mathrm{~K}$; Density of the substrate material ' $\rho_{s}$ ' and deposition material ' $\rho_{d}$ ' = $4430 \mathrm{~kg} / \mathrm{m}^{3}$; Specific heat of the substrate material ' $\mathrm{C}_{p s}$ ' and deposition material ' $\mathrm{C}_{p d}$ ' $=526.3$ $\mathrm{J} / \mathrm{kgK}$; Thermal diffusivity of the substrate material ' $\alpha_{s}$ ' $=2.87 \times 10^{-6} \mathrm{~m}^{2} / \mathrm{s}$; Values of the 
variable parameters corresponding to experiment no. 1 as mentioned in Table 3 (micro-plasma power ' $P$ ' $=418 \mathrm{~W}$; volumetric feed rate of the deposition material ' $f_{v}$ ' $=7.9 \times 10^{-9} \mathrm{~m}^{3} / \mathrm{s}$; relative speed between the worktable and deposition head ' $v$ ' $=8.66 \times 10^{-4} \mathrm{~m} / \mathrm{s}$ ).

This gave $9.02 \%$ dilution for experiment no. 1. Similarly, dilutions for parametric combinations of experiment no. 2 to 9 were calculated and are presented in Table 2 .

\section{Prediction of Dilution by Finite Element Simulation}

The area of dilution depends on the amount of heat conducted between the substrate material and melt pool. Three dimensional FES has been used to predict temperature distribution within substrate and deposition material to enable prediction of dilution of singlelayer single-track deposition of Ti-6Al-4V powder on the substrate of same material by MPTAAM process. FES was done using ANSYS 17.2 software. Both substrate material having dimensions of $100 \mathrm{~mm} \times 50 \mathrm{~mm} \times 22 \mathrm{~mm}$ and the deposited material were discretized using SOLID70 element type having a cubic element of $1 \mathrm{~mm}$ length as shown in Fig. 2. The movement of the micro-plasma arc has been simulated by applying the value of actual heat flow rate per unit volume. The single-layer single-track deposition phenomenon on the substrate material has been simulated by using the element "birth and death" technique. In which, at the beginning of the deposition process, elements in deposition zone are at the death state. Birth of the new elements over the substrate material take place as the micro-plasma torch travels along the deposition direction. Process of micro-plasma torch travel and birth of elements continue to take place until simulation of the single-layer single track deposition is completed.

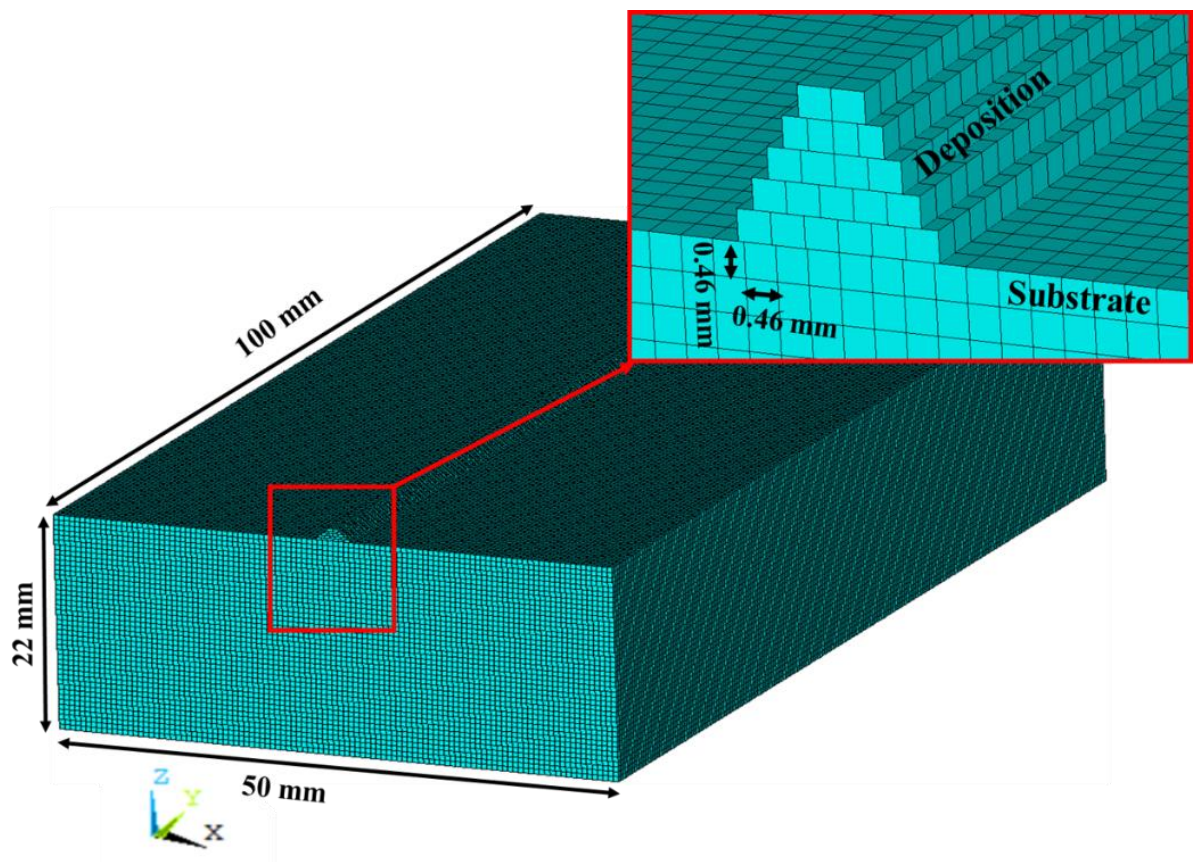


Fig. 2: Discretized geometry of the substrate and deposited material used in 3D-FES with inset showing its magnified view.

Following heat conduction equation was used to compute temperature distribution in the melt pool [16]:

$$
\rho_{s} C_{p s}^{*}\left(\frac{\partial T}{\partial t}\right)=q+\nabla \cdot\left(K_{s}^{*} \nabla T\right)
$$

Here, $\rho_{s}, C_{p s}^{*}$, and $K_{s}{ }^{*}$ are respectively density $\left(\mathrm{Kg} / \mathrm{m}^{3}\right)$; modified specific heat $(\mathrm{J} / \mathrm{Kg} \mathrm{K})$ and modified thermal conductivity of the substrate material $(\mathrm{W} / \mathrm{m} \mathrm{K}) ; q$ actual heat flow rate $\left(\mathrm{W} / \mathrm{m}^{3}\right) ; t$ is instant of time at which micro-plasma arc strikes the substrate material (s); and $T$ instantons temperature of melt pool at time $t(\mathrm{~K})$. Following boundary conditions were used in 3D-FES of single-layer single-track deposition by MPTAAM:

- Initial condition: At the starting point of the deposition process when time $t=0$; the temperature ' $T$ ' of substrate material is at ambient temperature $T_{i}$, i.e.,

$$
T=T_{i}(=298 \mathrm{~K})
$$

- Actual heat flow rate per unit volume ' $q$ ' $\left(\mathrm{W} / \mathrm{m}^{3}\right)$ from the micro-plasma arc is calculated by multiplying the value of micro-plasma heat transfer efficiency ' $\eta_{a}$ ' with the theoretical heat flow rate per unit volume ' $q(X, Y, Z)$ '. Nikam and Jain [16] have assumed microplasma arc to be a Gaussian heat source because it is symmetric distribution of heat flow rate about its center which has its maximum value. Consequently, following expression has been used for theoretical heat transfer rate by micro-plasma:

$$
q(X, Y, Z)=\sigma_{e s}\left(\frac{V}{L}\right)^{2} e^{\frac{-\left(X^{2}+Y^{2}\right)}{r_{m}^{2}}}
$$

Where, $\sigma_{e s}$ is electrical conductivity of the substrate material $\left(\mathrm{ohm}^{-1} \mathrm{~m}^{-1}\right) ; V$ is voltage applied to micro-plasma arc (Volts); $L$ is stand-off distance between micro-plasma torch and substrate material $(\mathrm{mm}) ; q(X, Y, Z)$ is theoretical heat flow rate at a point having coordinates $\mathrm{X}$ and $\mathrm{Y}$ with respect to the center of a heat source and $\mathrm{Z}$ with respect to standoff distance $\left(\mathrm{W} / \mathrm{m}^{3}\right) ; r_{m}$ is radius of micro-plasma arc $(\mathrm{m})$. Actual heat transfer rate ' $q$ ' is given by following relation:

$$
q=\eta_{a} q(X, Y, Z) \Rightarrow \eta_{a} \sigma_{e s}\left(\frac{V}{L}\right)^{2} e^{\frac{-\left(X^{2}+Y^{2}\right)}{r_{m}^{2}}}
$$

Where, $\eta_{a}$ is micro-plasma energy transfer efficiency; $\sigma_{e s}$ is electrical conductivity of the substrate material $\left(\mathrm{ohm}^{-1} \mathrm{~m}^{-1}\right) ; V$ is voltage applied to micro-plasma arc (Volts); $L$ is stand-off distance between the micro-plasma torch and the substrate material ( $\mathrm{mm})$; $q(X, Y, Z)$ is theoretical heat flow rate at a point having coordinates $\mathrm{X}$ and $\mathrm{Y}$ with respect 
to the center of a heat source and $\mathrm{Z}$ with respect to stand-off distance $\left(\mathrm{W} / \mathrm{m}^{3}\right)$; and $r_{m}$ is radius of micro-plasma arc $(\mathrm{m})$. In the present work, $5.8 \times 10^{5} \mathrm{ohm}^{-1} \mathrm{~m}^{-1}$ has been used as value of electrical conductivity ' $\sigma_{e s}$ ' of the substrate material i.e. Ti-6Al-4V powder [22] and value of micro-plasma heat transfer efficiency has been used as $60 \%$ as reported and justified by Nikam and Jain [16].

- Marangoni flow effect: Moving away of molten pool fluid having lower surface tension by the fluid having higher surface tension due to temperature gradient is referred as Marangoni flow effect. This has been considered by modifying thermal conductivity of the substrate material ' $K_{s}$ ' $(\mathrm{W} / \mathrm{m} \mathrm{K})$ as suggested by Alimardani et al. [23] using correction factor ' $C$ ' having value of 2.5 as suggested by Lampa et al. [24].

$$
K_{s}^{*}=C K_{s} \quad \text { if } T>T_{m s}
$$

Where, $T$ is instantaneous temperature of melt pool at time $t(\mathrm{~K}) ; T_{m s}$ is the melting temperature of the substrate material.

- Heat Loss from the substrate material to the surroundings due to radiation and convection has been evaluated by using following equation:

$$
\left(K_{s}^{*} \nabla T\right) \cdot n=\varepsilon_{s} \sigma_{s b c}\left(T_{m s}^{4}-T_{i}^{4}\right)+h_{c o n v}\left(T_{m s}-T_{i}\right)
$$

Here, $\varepsilon_{s}, T_{m s}$, and $K_{s}^{*}$ are emissivity, melting temperature $(\mathrm{K})$, and modified thermal conductivity $\left(\mathrm{W} / \mathrm{m} \mathrm{K}\right.$ ) of the substrate material respectively; $\sigma_{s b c}$ is Stefan-Boltzmann constant $\left(5.67 \times 10^{-8} \mathrm{~W} / \mathrm{m}^{2} \mathrm{~K}^{4}\right) ; h_{\text {conv }}$ is convective heat transfer coefficient of the substrate material $\left(\mathrm{W} / \mathrm{m}^{2} \mathrm{~K}\right) ; T_{i}$ is the ambient temperature $(298 \mathrm{~K})$; and $n$ is unit vector normal to surface of the molten pool in terms of unit vectors $\mathrm{i}, \mathrm{j}$, $\mathrm{k}$ along $\mathrm{X}, \mathrm{Y}$ and $\mathrm{Z}$ axes respectively.

- Phenomenon of latent heat of fusion has been considered by modifying the value of specific heat of the substrate material [25] and is expressed as

$$
C_{p s}^{*}=\frac{L_{f s}}{T_{m s}-T_{i}}+C_{p s}
$$

Where, $C_{p s}^{*}$ is the modified value of specific heat $(\mathrm{J} / \mathrm{kg} \mathrm{K})$ of the substrate material adding the value of latent heat of fusion ' $L_{f s}$ ' (i.e., $370 \mathrm{~kJ} / \mathrm{kg}$ for Ti-6Al-4V) to the specific heat of substrate material ' $C_{p s}$ ' $(\mathrm{J} / \mathrm{kg} \mathrm{K}) ; T_{m s}$ is the melting temperature of the substrate material $(\mathrm{K})$; and $T_{i}$ is the ambient temperature $(\mathrm{K})$.

- Temperature dependent properties of Ti-6Al-4V material: Table 1 presents temperature dependence of thermal conductivity, density and specific heat for the substrate and deposition materials along with other properties used in the present work. Fig. 3 shows variation of these material properties of Ti-6Al-4V alloy with respect to the temperature. 
Table 1: Chemical composition, physical properties and temperature dependent properties of the substrate and deposition materials [26].

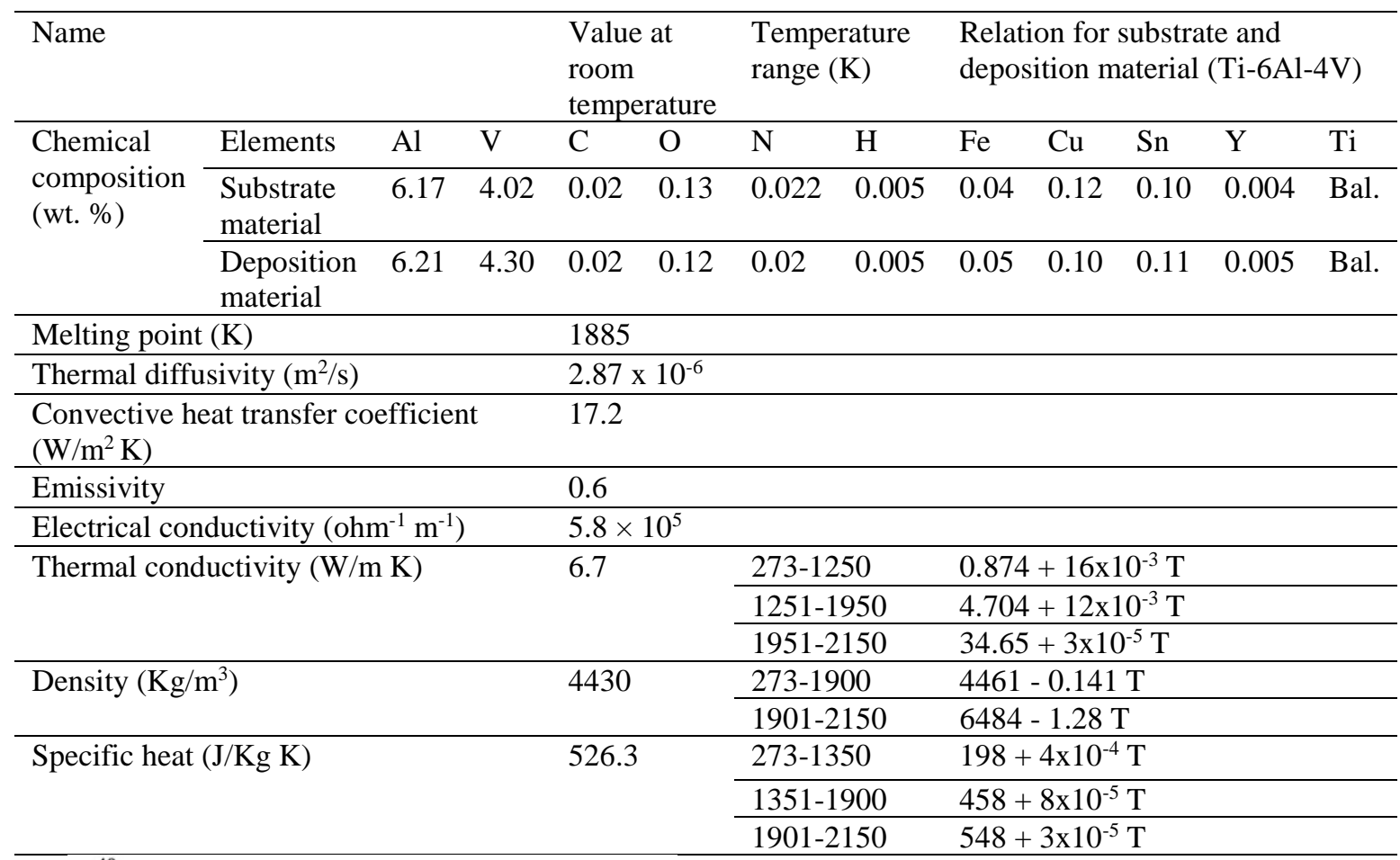

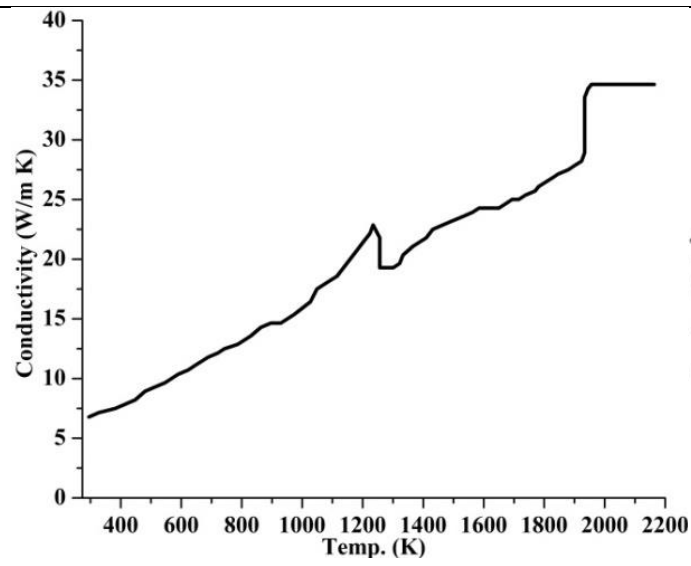

(a)

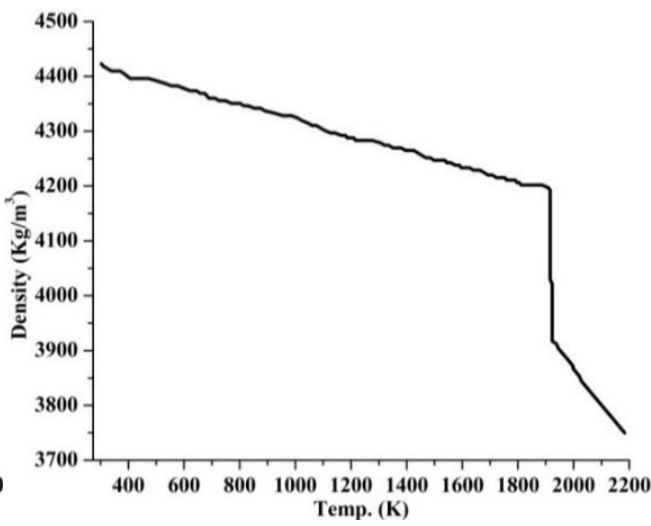

(b)

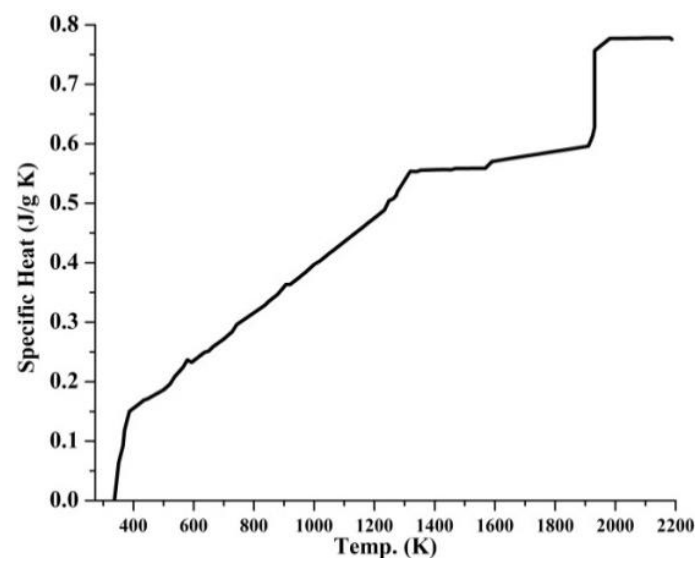

(c) 
Fig. 3: Variation of thermal properties of Ti-6Al-4V alloy with temperature (a) thermal conductivity; (b) density and (c) specific heat [26].

- Finite element simulation (FES) has been used in present study. FES has been validated by Nikam and Jain [17] for deposition of Ti-6Al-4V material on similar substrate material by using MPTAAM process. They compared the FES obtained thermal cycle with the experimental recorded thermal cycles and found that the FES slightly under predicts the thermal cycles with a maximum error of $2 \%$. Previously validated FES codes have been used in present study to simulate the dilution of MPTAAM process.

- Maximum temperature distribution graphs have been used to measure the width ' $w_{m}$ ' and height ' $h_{m}$ ' of the melt pool from FES. Figure 4 depicts distribution of maximum temperature along the width (Fig. 4a) and height (Fig 4b) of the substrate material. From these figures it can be observed that maximum temperature i.e. melting temperature of Ti$6 \mathrm{Al}-4 \mathrm{~V}(1950 \mathrm{~K})$ experienced along width of substrate is between $-1.4 \mathrm{~mm}$ to $1.4 \mathrm{~mm}$ (along $\mathrm{X}$-axis of Fig. 4a) therefore value of ' $w_{m}$ ' is $2.8 \mathrm{~mm}$. Similarly melting temperature of Ti6Al-4V i.e. $1950 \mathrm{~K}$ experienced along height of substrate is from $0 \mathrm{~mm}$ to $0.26 \mathrm{~mm}$ (along $\mathrm{x}$-axis of Fig. 4b) therefore value of ' $h_{m}$ ' is $0.26 \mathrm{~mm}$. Accuracy of these obtained values has been validated by using image processing method as described in following paragraphs.

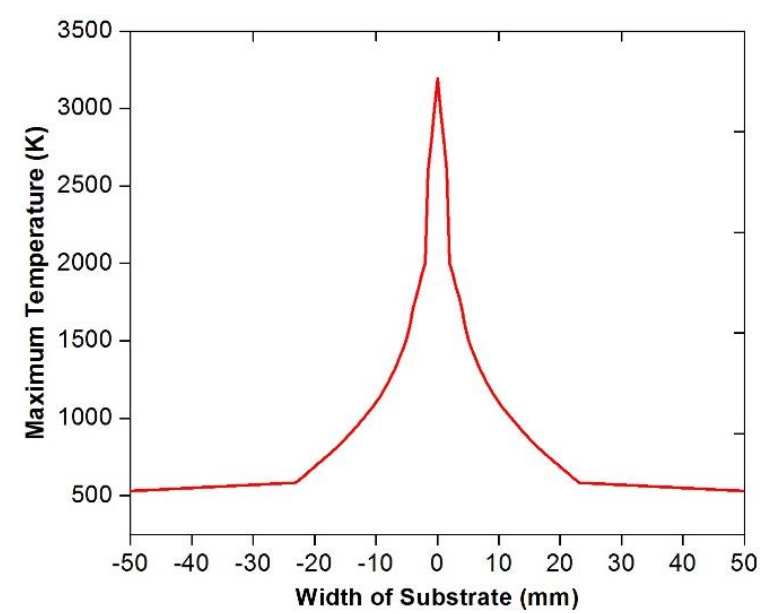

(a)

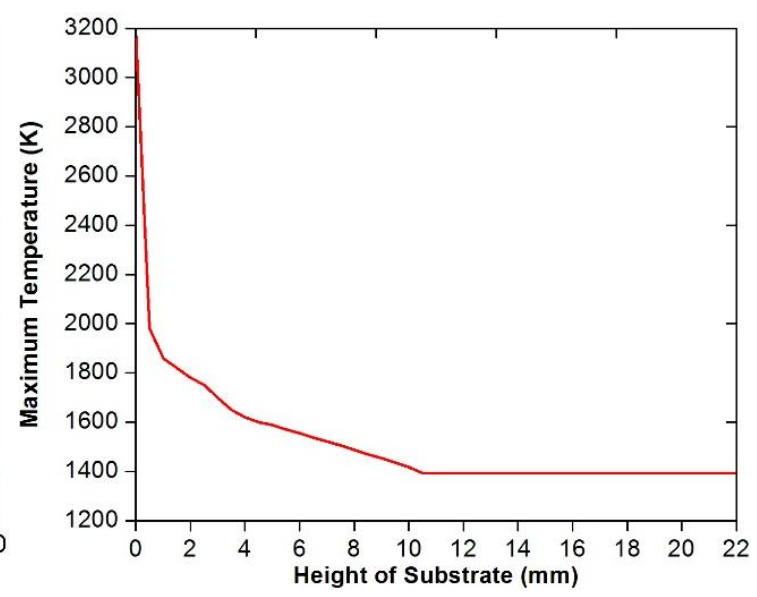

(b)

Fig. 4: Distribution of maximum temperature along the (a) width, and (b) height of substrate.

- Image processing method using MATLAB software has been used on the image captured from the 3D-FES to measure the width of the melt pool ' $w_{m}$ ' and height of the melt pool ' $h_{m}$ ', and height of deposition ' $h_{d}$ ' as shown in Fig. 5. Following equations presents details of their computation for parametric combination corresponding to experiment no. 1 mentioned in Table 2. It also prove that maximum temperature distribution graphs have good accuracy with image processing method. 


$$
\begin{aligned}
& \left.\begin{array}{l}
1750 \text { pixels in } 50 \mathrm{~mm} \text { width } \\
\text { els in } w_{m}(\mathrm{~m}) \text { width of the melt pool }
\end{array}\right\} \Rightarrow w_{m}=\frac{98 \times 50}{1750 \times 1000}=2.8 \times 10^{-3} \mathrm{~m} \\
& \left.\begin{array}{l}
762 \text { pixels in } 22 \mathrm{~mm} \text { height } \\
\text { in } h_{m}(\mathrm{~m}) \text { height of the melt pool }
\end{array}\right\} \Rightarrow h_{m}=\frac{22 \times 9}{762 \times 1000}=0.26 \times 10^{-3} \mathrm{~m} \\
& \left.\begin{array}{l}
762 \text { pixels in } 22 \mathrm{~mm} \text { height } \\
\text { xels in } h_{d}(\mathrm{~m}) \text { height of deposition }
\end{array}\right\} \Rightarrow h_{d}=\frac{22 \times 80}{762 \times 1000}=2.31 \times 10^{-3} \mathrm{~m}
\end{aligned}
$$

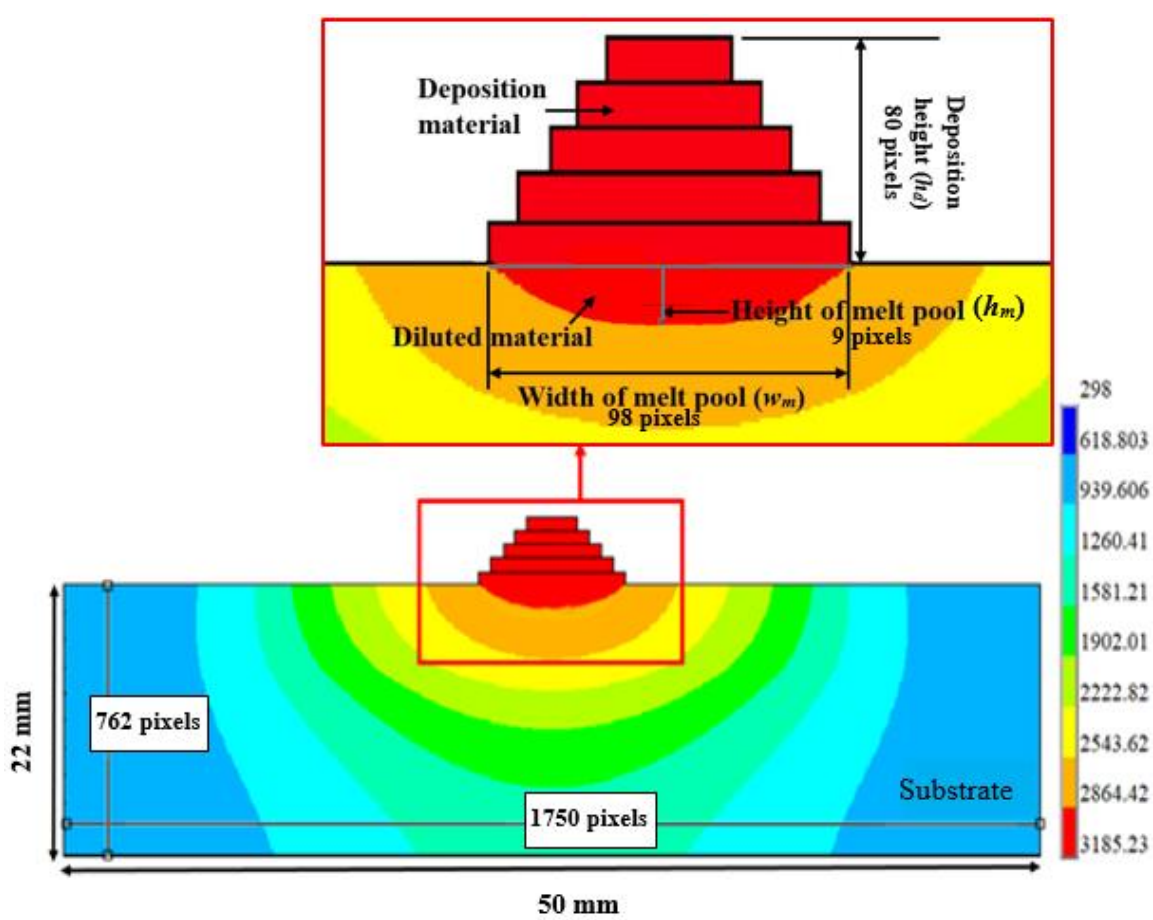

Fig. 5: Processed image of the melt pool obtained by 3D-FES for experiment no. 1 to predict its width and height with inset showing magnified view and dimensions of the melt pool.

Area of deposition ' $A_{d}$ ' can be calculated assuming shape of the deposition as an elliptical arc as reported and justified by Jhavar et al. [14]. Following equation gives its computation details:

$$
A_{d}=\frac{\pi}{4} w_{m} h_{d} \Rightarrow 5.079 \times 10^{-6}\left(m^{2}\right)
$$

Where, $w_{m}$ is width of melt pool (m); and $h_{d}$ is height of deposition (m).

Area of diluted substrate material ' $A_{s}$ ' can be calculated by assuming its shape also to be as an elliptical arc. Following equations gives its computation details:

$$
A_{s}=\frac{\pi}{4} w_{m} h_{m} \Rightarrow 0.572 \times 10^{-6}\left(m^{2}\right)
$$

Where, $w_{m}$ is width of melt pool (m); and $h_{m}$ is height of the melt pool (m).

The computed values of area of deposition from Eq. 19 and area of dilution from Eq. 20 were used in Eq. 1 to compute FES predicted dilution of single-layer single-track deposition with assumption that deposition profile remains uniform along the length of deposition so that 
areas of deposition and dilution can be used instead of their volumes. This obtained value of dilution is $10.1 \%$ for experiment no. 1 . Similarly, percentage of dilution for experiment no. 2 to 9 were calculated and are presented in Table 2 .

\section{Experimental Validation}

Values of dilution computed by the developed theoretical model (Eq. 10) and predicted by 3D-FES were experimentally validated by depositing single-layer single-track of Ti-6Al-4V powder on substrate of the same material by MPTAAM process using its experimental apparatus shown in Fig. 6. This apparatus was developed by integrating (i) 3-axis computer numerical control (CNC) worktable along with Arduino controller, (ii) $440 \mathrm{~W}$ power supply unit for micro-plasma torch along with plasma and shielding gas supply cylinders, (iii) powder feeding system for the deposition material comprising of DC motor and its power supply unit, hopper, gas supply unit, and deposition head consisting, (iv) micro-plasma torch, and (v) PC for controlling working of the apparatus.

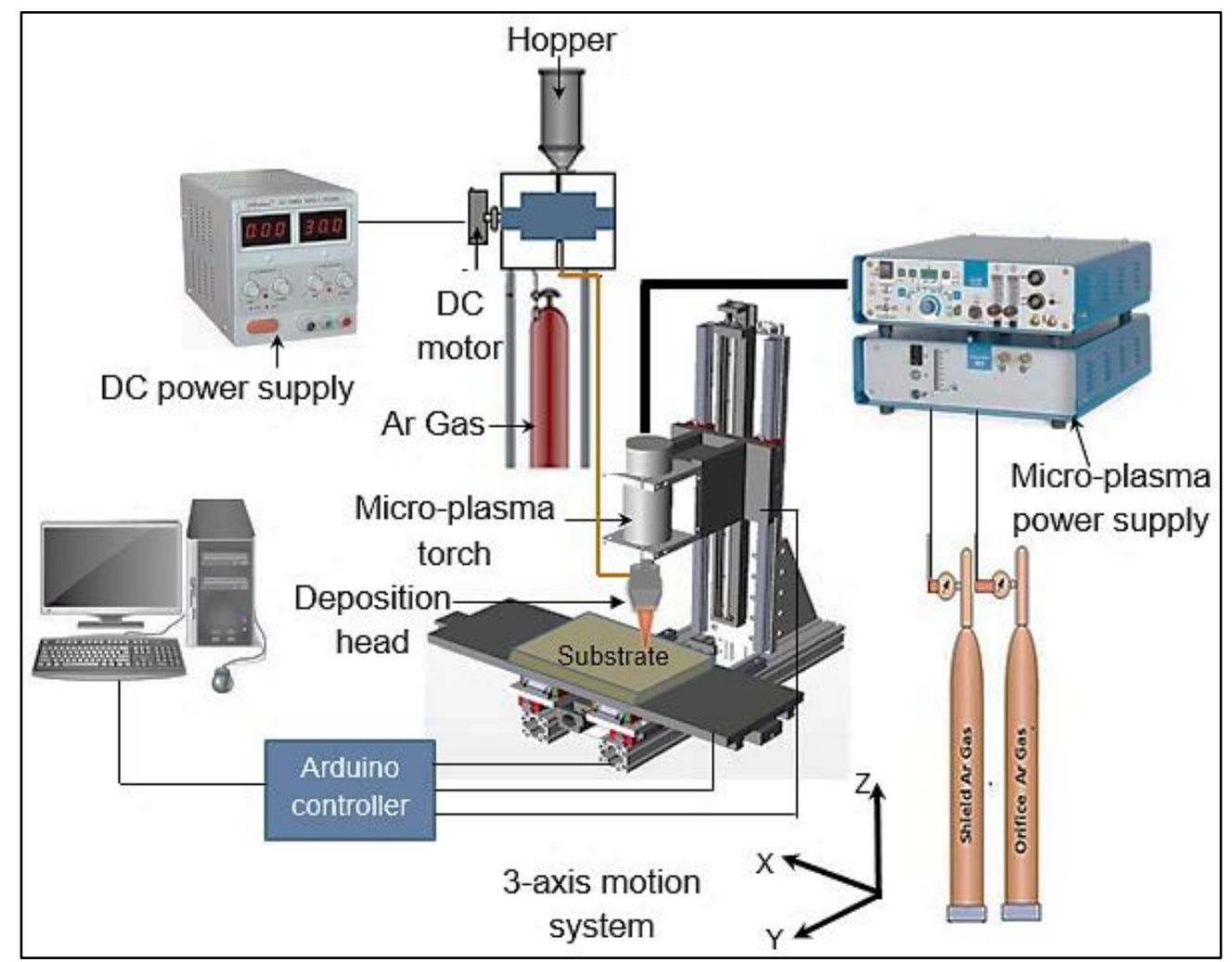

Fig. 6. Schematic view of experimental apparatus developed for powder deposition by MPTAAM process [27].

Titanium alloy Ti-6Al-4V is widely used in various applications such as automotive, biomedical, aerospace, sports marine etc. [28]. Therefore, its powder and bulk material were selected for the experimental verification. Their chemical compositions are presented in Table 
1. The experimental verification was conducted in two stages: pilot experiments were conducted in the $1^{\text {st }}$ stage to identify those feasible values of six considered parameters of MPTAAM process for the main experiments which ensured continuous single-layer singletrack deposition of Ti-6Al-4V powder. The identified values for the main experiments were: $0.3 \mathrm{Nl} / \mathrm{min}$ for plasma gas (i.e. argon) flow rate; $5 \mathrm{Nl} / \mathrm{min}$ for shielding gas (i.e. argon) flow rate; $10 \mathrm{~mm}$ for stand-off-distance; 418; 429; and $440 \mathrm{~W}$ for micro-plasma power; 5.64 x 10 $7.9 \times 10^{-9}$; and $1.01 \times 10^{-8} \mathrm{~m}^{3} / \mathrm{s}$ for volumetric feed rate of the deposition material, $8.66 \times 10^{-4}$; $9.5 \times 10^{-4}$; and $1.03 \times 10^{-3}(\mathrm{~m} / \mathrm{s})$ for relative speed between the worktable and deposition head. Taguchi's L ${ }_{9}$ orthogonal array was used for designing the main experiments performed in $2^{\text {nd }}$ stage by varying micro-plasma power, volumetric feed rage of the deposition material, and relative speed between the worktable and deposition head. Each experiment was repeated thrice. Deposition efficiency was calculated by measuring weight of the substrate material ' $W_{s}$ ' before deposition, combined weight of the deposition and the substrate material ' $W_{t}$ ' after deposition, computing weight of deposition material delivered to the melt pool ' $W_{p}$ ' using Eq. $5 \mathrm{~b}$, and then using these values in Eq. 5a. Same procedure was used for all replicates corresponding to each of the experiments and average value of deposition efficiency was calculated. They are presented in Table 2 which shows that deposition efficiency varies in the range from 76.4 to $89.3 \%$. Overall average of these nine values i.e. $83 \%$ was used in Eq. 10 for computing dilution by the developed theoretical model. Samples of the single-layer singletrack depositions of Ti-6Al-4V corresponding to 9 main experiments were cut transversely and prepared using the standard metallographic procedure for optical microscopy. Their images were captured using the optical microscope (model Stereo EZ4HD from Leica Inc. Germany). Figure 7 presents their optical images showing dilution and deposition areas which were measured using AutoCAD software. These measured values were used to compute experimental value of dilution using Eq. 1. Table 2 presents dilution values computed by the developed theoretical model (i.e. Eq. 10), predicted by 3D-FES and measured experimentally average values. Figure 8 depicts graphical comparison of these values. 


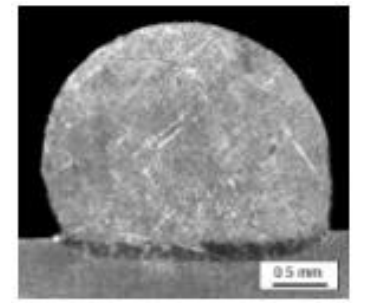

Expt. No. 1

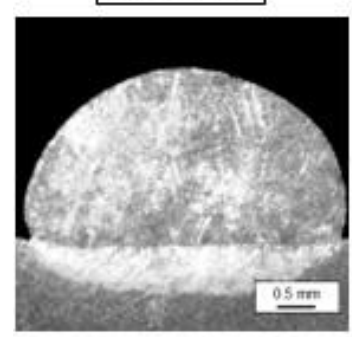

Expt. No. 4

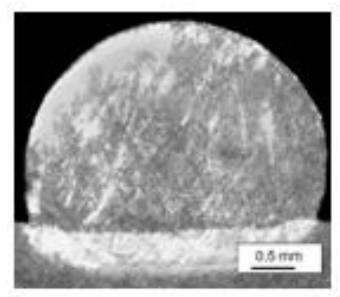

Expt. No. 7

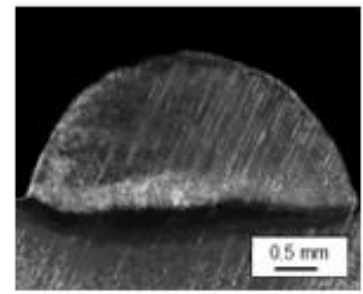

Expt. No. 2

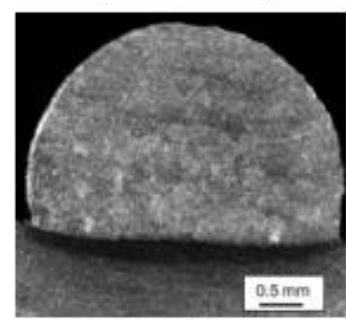

Expt. No. 5

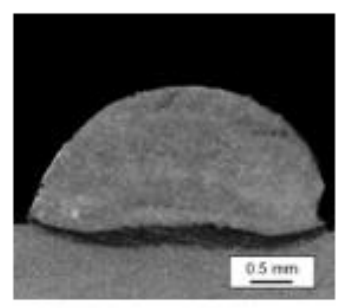

Expt. No. 8

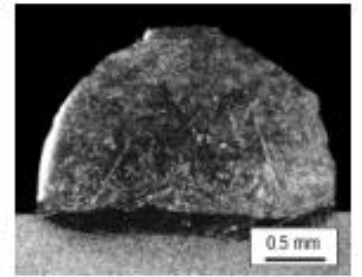

Expt. No. 3

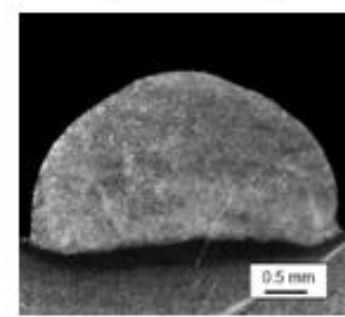

Expt. No. 6

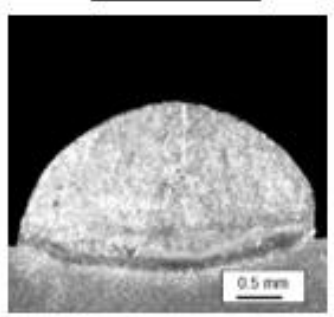

Expt. No. 9

Fig. 7: Optical images of the samples corresponding to the main experiments used in computing experimental values of dilution.

It can be observed from Table 2 and Fig. 8 that the theoretical model, FES and validation experiments give maximum value of dilution for experiment 7. Theoretical model and validation experiments give minimum value of dilution for experiment no. 9 whereas FES gave it for experiment no. 1. It can be seen from Fig. 8 that error between the theoretical model predicted and experimental values of dilution in a range from -15.79 to $2.73 \%$ and that error between the FES predicted and experimental values of dilution ranges from -1.89 to $17.23 \%$ implying that the theoretical model underpredicts the dilution whereas FES overpredicts it.

\subsection{Effect of process parameters on the dilution}

Effect of micro-plasma power (Fig. 9a), relative speed between the worktable and deposition head (Fig. 9b), and volumetric feed rate of the deposition material on the dilution (Fig. 9c) were studied using the dilution computed from the theoretical model and shown in the Figs. 9a-9c. Figure 9a depicts dilution increases with micro-plasma power at constant values of volumetric feed rate of the deposition material and relative speed between the worktable and deposition head. This is due to increase in volume of the molten substrate material and consequently dilution. Figure $9 \mathrm{~b}$ shows that dilution increases with relative speed 
between the worktable and deposition head. This is due to decrease in the deposition rate and consequently decrease in volume of the deposition thus increasing dilution. Figure 9c illustrates that dilution decreases with increase in volumetric feed rate of the deposition material. This is due to increase in volume of deposition which decreases the dilution.

Table 2: Theoretical model computed, FES predicted and experimental values of dilution of Ti-6Al-4V deposition on substrate of the same material by MPTAAM process for different parametric combinations of the experiments.

\begin{tabular}{|c|c|c|c|c|c|c|c|c|c|c|}
\hline \multirow{2}{*}{$\begin{array}{l}\text { Exp. } \\
\text { No. }\end{array}$} & \multicolumn{2}{|c|}{ Variable parameters } & \multicolumn{4}{|c|}{ FES predicted } & \multirow[b]{2}{*}{$\begin{array}{l}\text { Avg. value } \\
\text { of ' } \eta_{d} \text { ' } \\
\text { deposition } \\
\text { efficiency } \\
(\%) \\
3\end{array}$} & \multirow[b]{2}{*}{$\begin{array}{l}\text { Dilution } \\
\text { Computed } \\
\text { by the } \\
\text { developed } \\
\text { theoretical } \\
\text { model } \\
\text { (Eq. 10) }\end{array}$} & \multirow[b]{2}{*}{$\begin{array}{l}\text { Predicted } \\
\text { by FES }\end{array}$} & \multirow[b]{2}{*}{$\begin{array}{l}\text { Avg. } \\
\text { Experi- } \\
\text { mental } \\
\text { value }\end{array}$} \\
\hline & $\begin{array}{l}\text { Power } \\
\text { of } \\
\text { micro- } \\
\text { plasma } \\
\text { ' } P \text { ' (W) }\end{array}$ & $\begin{array}{l}\text { Volumetric } \\
\text { feed rate of } \\
\text { the } \\
\text { deposition } \\
\text { material ' } f_{v} \text { ' } \\
\left(\mathrm{m}^{3} / \mathrm{s}\right)\end{array}$ & $\begin{array}{l}\text { Relative } \\
\text { speed } \\
\text { between } \\
\text { the } \\
\text { worktable } \\
\text { and } \\
\text { deposition } \\
\text { head ' } v \text { ' } \\
(\mathrm{m} / \mathrm{s})\end{array}$ & $\begin{array}{l}\text { Height of } \\
\text { deposition } \\
(\mathrm{m}) \\
\times 10^{-3}\end{array}$ & $\begin{array}{l}\text { Width } \\
\text { of } \\
\text { melt } \\
\text { pool } \\
(\mathrm{m}) \\
\times 10^{-3}\end{array}$ & $\begin{array}{l}\text { Height } \\
\text { of } \\
\text { melt } \\
\text { pool } \\
(\mathrm{m}) \\
3 \times 10^{-3}\end{array}$ & & & & \\
\hline 1. & 418 & $7.9 \times 10^{-9}$ & $8.66 \times 10^{-4}$ & 2.31 & 2.8 & 0.26 & 86.2 & 9.02 & 10.1 & 10.39 \\
\hline 2. & 418 & $5.64 \times 10^{-9}$ & $1.03 \times 10^{-3}$ & 1.52 & 2.66 & 0.89 & 87.1 & 36.42 & 37.10 & 34.14 \\
\hline 3. & 418 & $7.9 \times 10^{-9}$ & $1.03 \times 10^{-3}$ & 1.72 & 2.68 & 0.20 & 79.5 & 10.99 & 10.85 & 12.82 \\
\hline 4. & 429 & $5.64 \times 10^{-9}$ & $9.5 \times 10^{-4}$ & 1.97 & 2.93 & 1.10 & 85.2 & 36.52 & 36.87 & 35.52 \\
\hline 5. & 429 & $7.9 \times 10^{-9}$ & $9.5 \times 10^{-4}$ & 2.06 & 3.15 & 0.30 & 78.3 & 11.17 & 12.66 & 12.10 \\
\hline 6. & 429 & $7.9 \times 10^{-9}$ & $1.03 \times 10^{-3}$ & 1.99 & 2.88 & 0.33 & 76.4 & 13.54 & 14.59 & 15.12 \\
\hline 7. & 440 & $5.64 \times 10^{-9}$ & $8.66 \times 10^{-4}$ & 2.02 & 3.3 & 1.19 & 89.3 & 38.71 & 37.21 & 36.45 \\
\hline 8. & 440 & $7.9 \times 10^{-9}$ & $1.03 \times 10^{-3}$ & 1.53 & 3.12 & 0.35 & 80.9 & 15.95 & 18.91 & 17.23 \\
\hline 9. & 440 & $1.01 \times 10^{-9}$ & $1.03 \times 10^{-3}$ & 1.6 & 3.1 & 0.23 & 79.3 & 8.25 & 11.11 & 9.5 \\
\hline
\end{tabular}

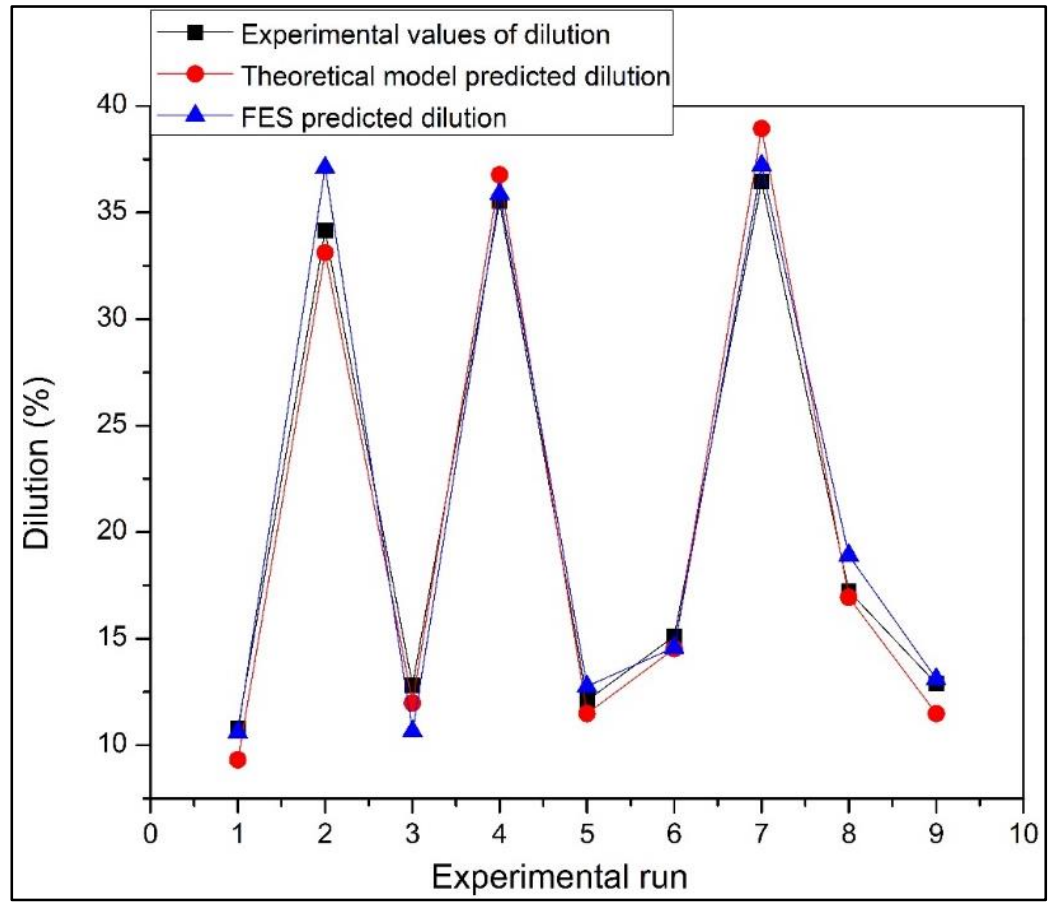

Fig. 8: Comparison of theoretical model predicted, FES predicted, and experimental values of dilution of Ti-6Al-4V powder deposition on same material substrate by MPTAAM process. 


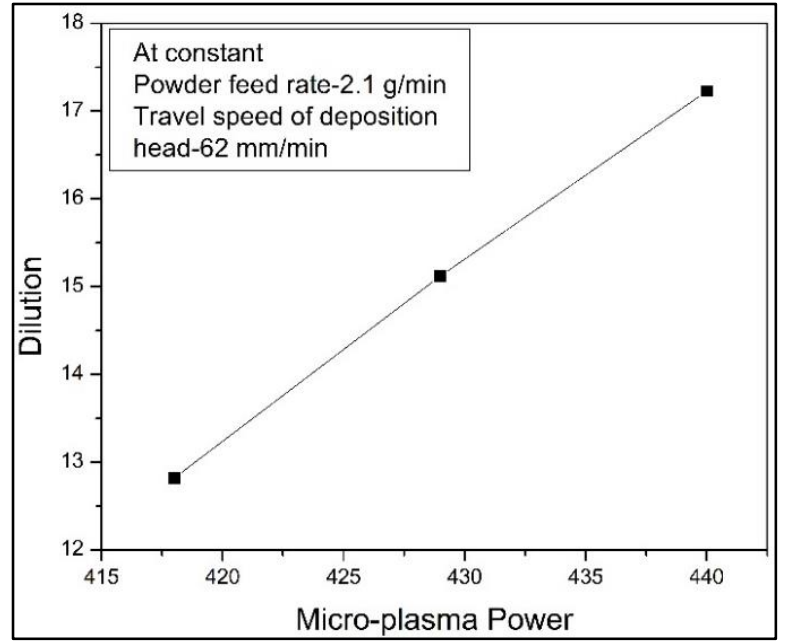

(a)

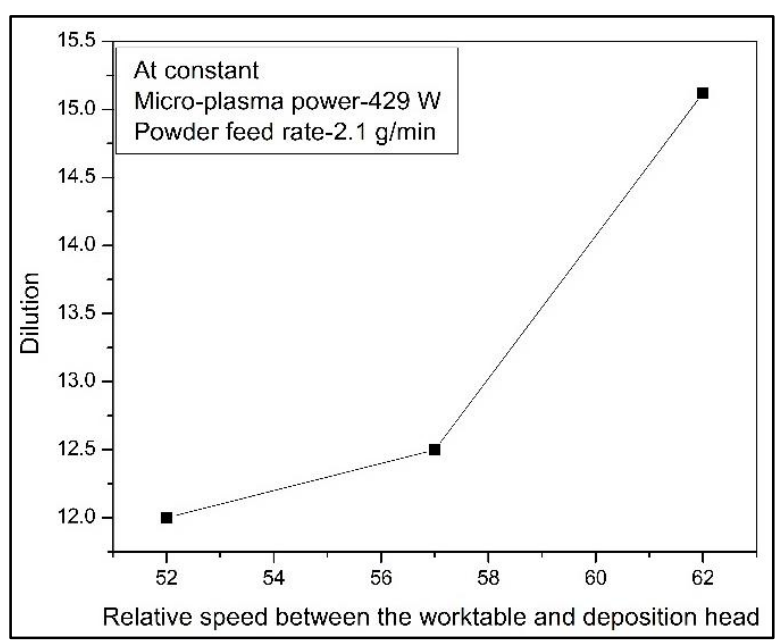

(b)

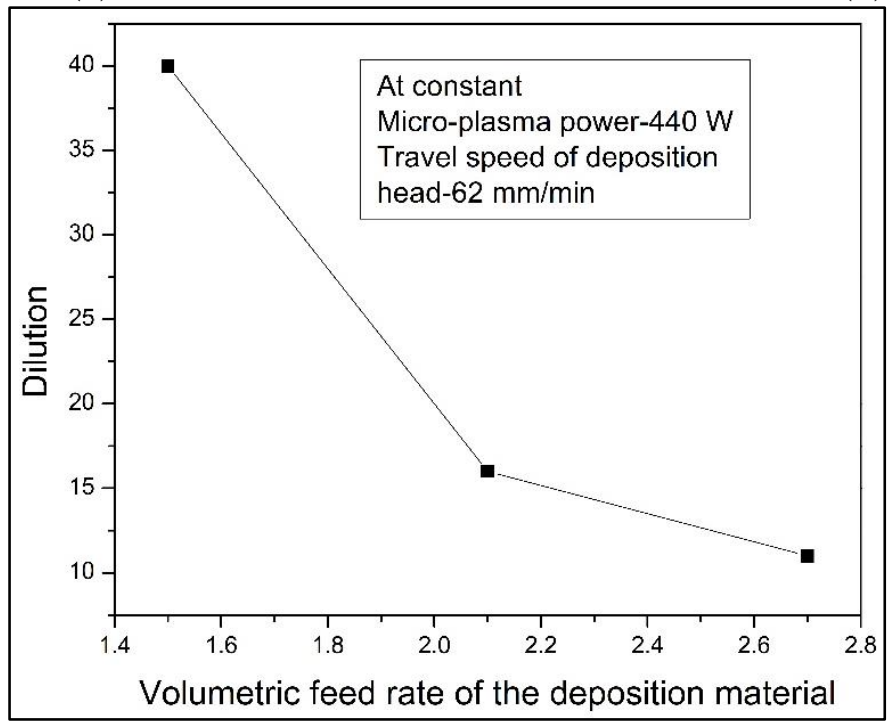

(c)

Fig. 9: Variation of dilution of single-layer single-track depositions with (a) micro-plasma power; (b) relative speed between worktable and deposition head; and (c) volumetric feed rate of the deposition material.

\section{Conclusions}

This paper described development of a generic theoretical model and FES to predict dilution of depositions by MPTAAM process. The theoretical model and FES predicted values were validated independently by comparing them with the experimental results of single-layer single-track deposition of Ti-6Al-4V powder on the substrate of the same material for the various parametric combinations of MPTAAM process. Following conclusions can be drawn from this study:

- The developed theoretical model and FES have independent ability to predict the dilution with good accuracy which has been confirmed with the help of experimental results of single-layer single-track deposition of Ti-6Al-4V powder on the substrate of the same 
material. They depend on thermo-physical properties of the substrate and deposition material, MPTAAM process parameters and process efficiencies. Therefore, developed theoretical model and FES can be called as generic to predict dilution of deposition by MPTAAM process.

- Error between the theoretical model predicted and experimental values of dilution is in range from -15.79 to $2.73 \%$ while, error between the FES predicted and experimental dilution ranges -1.89 to $17.23 \%$. This implies that the theoretical model underpredicts the dilution whereas FES overpredicts it. Deviation between the theoretical model predicted, FES-predicted and experimental values may be due to some of the simplifying assumptions made.

- For single-layer single track deposition of Ti-6Al-4V powder on the substrate of the same material, dilution increases with increase in micro-plasma power and relative speed between the worktable and deposition head whereas decreases with increase in volumetric feed rate of the deposition material.

- Maximum temperature distribution graph and image processing methods have ability to measure width and height of the melt pool and deposition geometry from the 3D-FES with very good accuracy.

\section{References}

[1] Lu X, Lin X, Chiumenti M, Cervera M, Hu Y, Ji X. In situ measurements and thermomechanical simulation of Ti-6Al-4V laser solid forming processes. Int J Mech Sci 2019;153-154:119-30. doi:10.1016/j.ijmecsci.2019.01.043.

[2] Xia M, Gu D, Yu G, Dai D, Chen H, Shi Q. Influence of hatch spacing on heat and mass transfer, thermodynamics and laser processability during additive manufacturing of Inconel 718 alloy. Int J Mach Tools Manuf 2016; 109:147-157. doi:10.1016/j.ijmachtools.2016.07.010.

[3] Xin H, Sun W, Fish J. Discrete element simulations of powder-bed sintering-based additive manufacturing. Int J Mech Sci 2018;149:373-92. doi:10.1016/j.ijmecsci.2017.11.028.

[4] Liu B, Chen H, Cao W. A novel method for tailoring elasticity distributions of functionally graded porous materials. Int J Mech Sci 2019; 157-158:457-70. doi:10.1016/j.ijmecsci. 2019.05.002. 
[5] Nikam SH, Jain NK, Jhavar S. Thermal modeling of geometry of single-track deposition in micro-plasma transferred arc deposition process. J Mater Process Technol 2016; 230:121-130. doi:10.1016/j.jmatprotec.2015.11.022.

[6] Belhabib S, Guessasma S. Compression performance of hollow structures: From topology optimisation to design 3D printing. Int J Mech Sci 2017;133:728-39. doi:10.1016/j.ijmecsci.2017.09.033.

[7] Sawant MS, Jain NK. Investigations on wear characteristics of Stellite coating by microplasma transferred arc powder deposition process. Wear 2017; 379: 155-164. doi.org/10.1016/j.wear.2017.02.041

[8] Sawant MS, Jain NK. Characteristics of single-track and multi-track depositions of Stellite by micro-plasma transferred arc powder deposition process. J Mater Eng Perform 2017; 26: 4029-4039. doi:10.1007/s11665-017-2828-y.

[9] Sawant MS, Jain NK. Evaluation of Stellite coatings by $\mu$-PTA powder, laser, and PTA deposition processes. Mater Manuf Process 2018; 33: 1043-1050. doi:10.1080/10426914.2017.1364764.

[10] Liu J, Li J. Direct fabrication of thin-wall parts by laser cladding. J Manuf Process 2006; 8(1): 1-7. doi.org/10.1016/S1526-6125(06)70096-2

[11] Hua T, Jing C, Xin L, Fengying Z, Weidong H. Research on molten pool temperature in the process of laser rapid forming. J Mater Process Technol 2008; 198(1-3): 454-462. doi.org/10.1016/j.jmatprotec.2007.06.090

[12] Tan H, Chen J, Zhang F, Lin X, Ã WH. Process analysis for laser solid forming of thinwall structure. Int J Mach Tools Manuf 2010; 50: 1-8. doi:10.1016/j.ijmachtools.2009.10.003.

[13] Cheikh HE, Courant B, Hascoët JY, Guillén R. Prediction and analytical description of the single laser track geometry in direct laser fabrication from process parameters and energy balance reasoning. J Mater Process Technol 2012; 212(9): 1832-1839. doi.org/10.1016/j.jmatprotec.2012.03.016

[14] Jhavar S, Jain NK, Paul CP. Enhancement of deposition quality in micro-plasma transferred arc deposition process. Mater Manuf Process 2014; 29(8): 1017-1023. doi.org/10.1080/10426914.2014.892984

[15] Ya W, Pathiraj B, Liu S. 2D modelling of clad geometry and resulting thermal cycles during laser cladding. J Mater Process Technol 2016; 230: 217-232. doi.org/10.1016/j.jmatprotec.2015.11.012 
[16] Nikam SH, Jain NK, Three-dimensional thermal analysis of multi-layer metallic deposition by micro-plasma transferred arc process using finite element simulation. $\mathbf{J}$ Mater Process Technol 2017; 249: 264-273. doi:10.1016/j.jmatprotec.2017.05.043.

[17] Shrestha S,Chou K. A build surface study of powder-bed electron beam additive manufacturing by 3D thermo-fluid simulation and white-light interferometr. Int $\mathrm{J}$ Mach Tools Manuf 2017; 121: 37-49. doi:10.1016/j.ijmachtools.2017.04.005.

[18] Lee EM, Shin GY, Yoon HS, Shim DS. Study of the effects of process parameters on deposited single track of M4 powder based direct energy deposition. J Mech Sci Technol 2017; 31(7): 3411-3418. doi.org/10.1007/s12206-017-0239-5

[19] Nabhani M, Razavi RS, Barekat M. An empirical-statistical model for laser cladding of Ti-6Al-4V powder on Ti-6Al-4V substrate. Opt Laser Technol 2018; 100: 265-271. doi.org/10.1016/j.optlastec.2017.10.015

[20] Reddy L, Preston SP, Shipway PH, Davis C, Hussain T. Process parameter optimization of laser clad iron- based alloy: Predictive models of deposition efficiency, porosity and dilution. Surf Coat Technol 2018; 349: 198-207. doi:10.1016/j.surfcoat.2018.05.054.

[21] Okada A. Application of melting efficiency in welding and its problems, J Jpn Weld Soc 1977; 46 (2): 55-61. doi.org/10.2207/qjjws1943.46.2_53

[22] NDT resource center. 2014: https://www.nde-ed.org/GeneralResources/ MaterialProperties/ET/Conductivity_Ti.pdf.

[23] Alimardani M, Toyserkani E, Huissoon JP. Three-dimensional numerical approach for geometrical prediction of multilayer laser solid freeform fabrication process, J Laser Appl 2007; 19(1): 14-25. doi.org/10.2351/1.2402518

[24] Lampa C, Kaplan AFH, Powell J. An analytical thermodynamic model of laser welding. J Phys D: Appl Phys 1997; 30: 1293-1299. http://iopscience.iop.org/0022-3727/30/9/004

[25] Nikam SH, Jain NK. Modeling and prediction of residual stresses in additive layer manufacturing by microplasma transferred arc process using finite element simulation Transactions of ASME: J of Manuf Sci and Eng. 2019; 141(6): 061003-1- 061003-14. doi: $10.1115 / 1.4043264$

[26] Mills KC. Recommended values of thermo-physical properties for selected commercial alloys. Woodhead Publishing, Cambridge 2002; 211-217. ISBN 978-1-85573-569-9

[27] Sawant MS, Jain NK. Investigations on additive manufacturing of Ti-6Al-4V by $\mu-$ plasma transferred arc powder deposition process Transactions of ASME: J of Manuf Sci and Eng. 2018; 140: 081014-10-81014-11. doi: 10.1115/1.4040324 
[28] Julien R, Velay V, Vidal V, Dahan Y, Forestier R, Rézaï-aria F. Characterization and modeling of forged Ti-6Al-4V Titanium alloy with microstructural considerations during quenching process. Int J Mech Sci 2018;142-143:456-67. doi:10.1016/j.ijmecsci.2018.05.023. 